\title{
SCIDOC
}

\author{
International Journal of Dentistry and Oral Science (IJDOS) \\ ISSN: 2377-8075
}

\section{Estimating The Antimicrobial Efficacy Of Calcium Hydroxide With Different Carrier Vehicles}

Research Article

Edala Venkata Gana Karthik ${ }^{1}$, Madhusudhan², EMG Subramanian³ ${ }^{3}$ Dhanraj Ganapathy ${ }^{*}$

${ }^{1}$ Graduate Student, Department of Prosthodontics, Saveetha Dental college and Hospitals, Saveetha Institute of medical and Technical Sciences, Saveetha University, Chennai, India.

${ }^{2}$ Senior Lecturer, Department of Pedodontics, Saveetha Dental College, Saveetha Institute of Medical and Technical Sciences, Chennai, India.

${ }^{3}$ Professor, Department of Pedodontics, Saveetha Dental College, Saveetha Institute of Medical and Technical Sciences Chennai, India.

${ }^{4}$ Professor and Head of Department of Prosthodontics, Saveetha Dental College and Hospitals, Saveetha Institute of Medical and Technical Sciences, Saveetha University, 162, Poonamallee High Road, Chennai - 600077, Tamil Nadu, India.

\section{Abstract}

Introduction: Since its introduction in 1920 (Hermann 1920), calcium hydroxide has been widely used in endodontics. It is a strong alkaline substance, which has a $\mathrm{pH}$ of approximately 12.5. In an aqueous solution, calcium hydroxide dissociates into calcium and hydroxyl ions. Bacterial micro flora of primary endodontic infections differs vastly from secondary or persistent peri radicular lesions. The most frequent survivors present in a very high proportion of root canal failure cases are Enterococcus faecalis with the prevalence of $24 \%-77 \%$ and Candida albicanswith the prevalence of $6 \%-18 \%$.

Materials \& Methods: The study was done by assessing zone of inhibition forEnterococcusfaecalis and Candida albicanswith 4 different carriers for calcium hydroxide.The statistical package SPSS

(Statistical package for social science) and Microsoft Excel was used for statistical analysis.

Results: The obtained results state that calcium hydroxide mixed with saline showed an increased antimicrobial effect on facultative anaerobes such aE. faecalis and C. albicans, with calcium hydroxide mixed with distilled water as standard.

Conclusion: The obtained results state that Saline was promoting the antibiotic effect whereas Local anaesthesia and MTA were inhibiting the antibiotic activity of calcium hydroxide.

Keywords: Calcium Hydroxide; Antimicrobial Effect; MTA; Local Anaesthesia; Saline.

\section{Introduction}

The prevention and control of pulpal and peri-radicular infections is essentially projected toward the success of endodontic treatment [1]. It is clear that the outcome of the endodontic therapy depends on their reduction or elimination of the microorganisms involving the peri-radicular lesions. Complete chemo-mechanical preparation may be considered an essential step in root canal disinfection.[2] However, it is totally difficult to accomplish total elimination of bacteria.Since its introduction in 1920 (Hermann 1920), calcium hydroxide has been widely used in endodontics. [3] It is a strong alkaline substance, which has a $\mathrm{pH}$ of approximately 12.5. In an aqueous solution, calcium hydroxide dissociates into calcium and hydroxyl ions. Numerous biological properties have been attributed to calcium hydroxide, such as antimicrobial activity, inhibition of tooth resorption, induction of repair, tissuedissolving ability and by hard tissue formation [4]. Because of all the beneficiary effects calcium hydroxide is been recommended for use in several clinical situations [5].

Recent results show that calcium hydroxide paste used as a dressing in carefully instrumented and irrigated root canals kills the bacteria so effectively that the treatment of initially infected root canals can be completed at the second visit [6]. Calcium hydroxide was originally introduced to the field of endodontics by Herman in 1920 as a pulp-capping agent. It is a white odourless powder with the formula $\mathrm{Ca}(\mathrm{OH})_{2}$ and has a molecular weight of 74.08. $\mathrm{Ca}(\mathrm{OH})_{2}$ has low solubility in water (about $1.2 \mathrm{gm}-\mathrm{L}^{-1}$ at 25),

*Corresponding Author:

Dhanraj Ganapathy,

Professor and Head of Department of Prosthodontics, Saveetha Dental College and Hospitals, Saveetha Institute of Medical and Technical Sciences, Saveetha University, 162, Poonamallee High Road, Chennai - 600077, Tamil Nadu, India. Tel: 9841504523

E-mail: dhanrajmganapathy@yahoo.co.in

Received: May 28, 2021

Accepted: June 16,202

Published: July 01, 2021

Citation: Edala Venkata Gana Karthik, Madhusudhan, EMG Subramanian, Dhanraj Ganapathy. Estimating The Antimicrobial Efficacy Of Calcium Hydroxide With Different Carrier Vehicles. Int J Dentistry Oral Sci. 2021;8(7):2941-2945. doi: http://dx.doi.org/10.19070/2377-8075-21000597

Copyright: Dhanraj Ganapathy ${ }^{\circ} 2021$. This is an open-access article distributed under the terms of the Creative Commons Attribution License, which permits unrestricted use, distribution and reproduction in any medium, provided the original author and source are credited. 
which decreases as the temperature rises.

The dissociation coefficient of $\mathrm{Ca}(\mathrm{OH})_{2}(0.17)$ permits a slow, controlled release of both calcium and hydroxyl ions $[6,7]$. The low solubility is a good clinical characteristic because a long period is necessary for $\mathrm{Ca}(\mathrm{OH})_{2}$ to become soluble in tissue fluids when in direct contact with vital tissues. $\mathrm{Ca}(\mathrm{OH})$, has a high $\mathrm{pH}$ (about 12.5-12.8), is insoluble in alcohol, and is chemically classified as a strong base.(8) Its main actions result from the ionic dissociation of th $\mathrm{Ca}_{2}^{+}$and $\mathrm{OH}^{-}$ions and their effect on vital tissues, such as inducing hard tissue deposition and being antibacterial. $\mathrm{Ca}(\mathrm{OH})_{2}$ dissociates into calcium and hydroxyl ions on contact with aqueous fluids. $\mathrm{Ca}(\mathrm{OH})_{2}$ in water has a thixotropic behaviour, which means that it will be very fluid when agitated. When $\mathrm{Ca}(\mathrm{OH})_{2}$ is exposed to carbon dioxide $\left(\mathrm{CO}_{2}\right)$ or carbonate ions $\left(\mathrm{CO}_{3}\right)$ in biological tissue, the dissociation of the chemical leads to the formation of calcium carbonate $\left(\mathrm{CaCO}_{3}\right)$ and an overall consumption of $\mathrm{Ca}^{+}$ions [9].

Currently, this chemical substance is acknowledged as one of the most effective antimicrobial dressings during endodontic therapy $[9,10]$. However, one study showed that after 30 days of exposure to carbon dioxide, six preparations of $\mathrm{Ca}(\mathrm{OH})_{2}$ still maintained a purportedly bactericidal $\mathrm{pH}$ within the root canal. In studies that have demonstrated the antimicrobial efficacy of calcium hydroxide, the root canals had been dressed for at least 1 month. It is not clear, however, what minimum time might be needed for a calcium hydroxide dressing to achieve an optimal antibacterial effect [10].

The main etiological agents of pulp necrosis and peri-radicular lesions are the microorganisms, bacteria, and their products.Candidaalbicans is the most common species of fungi cultured from root canals of teeth with failed endodontic treatment. Because of collagenolytic activity, it may be possible for the yeast to use dentin as a nutrient source and promote colonization in the root canal. Another organism commonly found in cases of failed endodontic infections and endodontic flare-ups is Enterococcus faecalis. It has the ability to survive in root canal system as a single organism without the support of other bacteria and is small enough to proficiently invade and live within the dentinal tubules [11]. Many studies have reported that $\mathrm{C}$. albicans and $\mathrm{E}$. faecalis are able to invade dentinal tubules to variable depth. [12] So, to ensure complete elimination of root canal bacteria, an effective antimicrobial agent in the root canal is required for a predetermined time for complete eradication of any remaining bacteria $[12,13]$.

Calcium hydroxide has been widely used as an intracanal medicament in endodontics, and it has been demonstrated that it is very effective against obligate anaerobes but facultative anaerobes like C. albicans and E. faecalis have been reported to be resistant to the antimicrobial effect of calcium hydroxide [12-14]. Therefore, the purpose of the present study was to assess in vitro antimicrobial activity of Calcium hydroxide mixed with different vehicles against E. faecalis and C. albicans by agar diffusion method.Our research experience has prompted us in pursuing this study [1524].

\section{Materials And Methods}

The test organisms chosen to use for this study were C. albicans and $\mathrm{E}$. faecalis as they are the most frequently isolated bacterial species from the root canals of endodontically failed teeth. Culture of C. albicans and E. faecalis were grown on Nutrient agar and incubated for $24 \mathrm{~h}$ at $37^{\circ} \mathrm{C}$. All solutions were at a concentration of $100 \mu \mathrm{l}$. [25, 26].

Intracanal medicaments were prepared for four solutions: Solution I: calcium hydroxide $\left[\mathrm{Ca}(\mathrm{OH})_{2}\right]+$ saline Solution II: calcium hydroxide $\left[\mathrm{Ca}(\mathrm{OH})_{2}\right]+$ distilled water Solution III: calcium hydroxide $\left[\mathrm{Ca}(\mathrm{OH})_{2}\right]+$ Local anaesthesia Solution IV: calcium hydroxide $\left[\mathrm{Ca}(\mathrm{OH})_{2}\right]+$ MTA (Mineral trioxide aggregate)

Diluted solution was transferred to their respective medium for culture. Plates were incubated for $24 \mathrm{~h}$ at $37^{\circ} \mathrm{C}$. Zone of inhibition was measured after adding the four different solutions to the culture plates.

The statistical package SPSS (Statistical package for social science) and Microsoft Excel was used for statistical analysis.

\section{Results}

The obtained results state that calcium hydroxide mixed with saline showed an increased antimicrobial effect on facultative anaerobes such a E. faecalis and C. albicans, with calcium hydroxide mixed with distilled water as standard. Calcium hydroxide combined with MTA reduces the anti-microbial efficacy of calcium hydroxide.

\section{Discussion}

Root canal irrigating solutions and intracanal medicaments are used to eliminate the bacteria from the root canals [27]. Antibiotics are used in dentistry both systemically and topically. During systemic administration of antibiotics, negligible concentrations reach the root canal, whereas during the local administration of antibiotics, greater concentrations can be used as intracanal medicaments, to decrease systemic consequences and complications. $[11,28]$. Dealing with the complexity of root canal infection, a single irrigant or a medicament could not result in effective sterilization of the root canal [27-29]. Combination of irrigants or

Table 1. Zone Of Inhibition In Millimeters.

\begin{tabular}{|c|c|c|}
\hline Solutions $(\mathbf{1 0 0} \boldsymbol{\mu} \mathbf{l})$ & E. faecalis & C. albicans \\
\hline calcium hydroxide $[\mathrm{Ca}(\mathrm{OH}) 2]+$ saline & $18 \mathrm{~mm}$ & $21 \mathrm{~mm}$ \\
\hline calcium hydroxide $[\mathrm{Ca}(\mathrm{OH}) 2]+$ distilled water & $17 \mathrm{~mm}$ & $20 \mathrm{~mm}$ \\
\hline calcium hydroxide $[\mathrm{Ca}(\mathrm{OH}) 2]+$ Local anaesthesia & $16 \mathrm{~mm}$ & $19 \mathrm{~mm}$ \\
\hline calcium hydroxide $[\mathrm{Ca}(\mathrm{OH}) 2]+\mathrm{MTA}($ Mineral trioxide aggregate) & $15 \mathrm{~mm}$ & $15 \mathrm{~mm}$ \\
\hline
\end{tabular}


Figure 1. Efficacy of each solution.

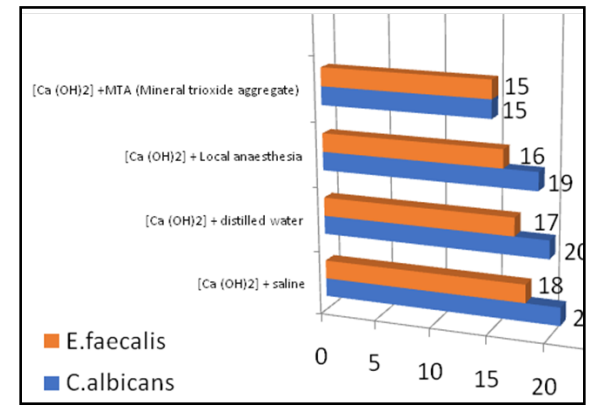

Figure 2. E.faecalis - Zone Of Inhibition.

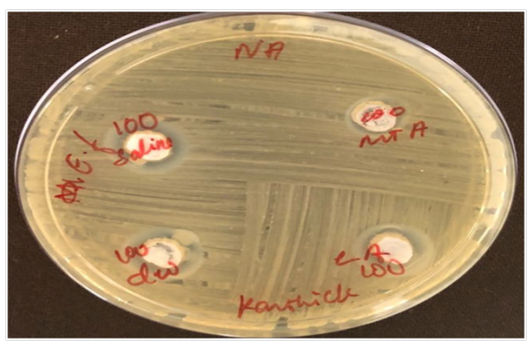

Figure 3. C. albicans - Zone Of Inhibition.

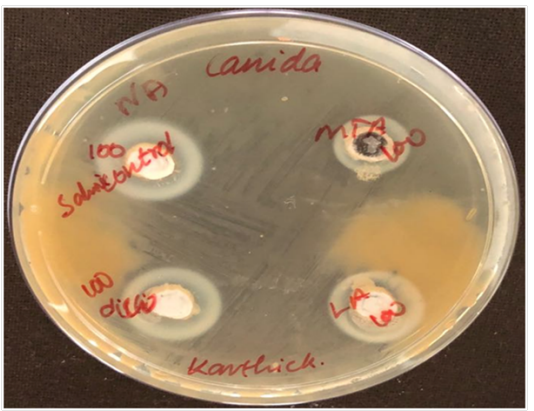

medicaments decreases the development of resistant bacterial strains and produces synergistic effect, whose antimicrobial action lasts longer and also sustains release of medicaments occurs. In the present study, $\mathrm{Ca}(\mathrm{OH})_{2}+$ saline has shown better antifungal efficacy against $\mathrm{C}$. albicans and against $\mathrm{E}$. faecalis compared with the remaining groups of solutions, with $\mathrm{Ca}(\mathrm{OH})_{2}+$ distilled water as standard, which is significant. $\mathrm{Ca}(\mathrm{OH})_{2}+$ MTA showed the least antimicrobial efficacy among the chosen vehicles [30].

Various methods have been describedfor the antimicrobial activity of endodontic disinfectants and medicaments. The generally accepted procedure worldwide for determining in vitro sensitivity under routine laboratory conditions is Agar diffusion test. The majority of research on Calcium hydroxide pastes has used the agar diffusion method. This method is simple, standard, and reproducible. Even though the agar method is one of the popular tests, it may have some limitations.Some factors (such as $\mathrm{pH}$ of the substrate, incubation period, toxicity, sensitivity, and diffusion capacity of the drug) may have an effect on the antimicrobial activity of the test materials in the plates. However, there is also evidence that agar diffusion tests show good correlation with other antimicrobial susceptibility tests [25]. Results of agar diffusion tests should be carefully examined when materials such as Calcium hydroxide are used, because its antibacterial effect is mainly obtained from its high alkalinity.With the presence of buffering agents in the culture medium, regardless of whether Calcium hydroxide can diffuse through agar plates very well, its $\mathrm{pH}$ may not reach sufficient level to give enough antimicrobial activity. Buffering ability of the agar media may alter its antimicrobial activity. On the other hand, similar buffering effect may be generated by tissue fluids and dentin in ex vivo or in vivo conditions [30, 31].

The effect of Calcium hydroxide on C. albicans is very controversial in the literature. In the present study, all Calcium hydroxide preparations were more effective on C. albicans than on $\mathrm{E}$. faecalis. [32] In contrast, it has been previously found that Calcium hydroxide is not an effective agent on C. albicans. However, there are some methodologic differences among these studies. [33] Waltimo et al. used saturated aqueous Calcium hydroxide, which has a high $\mathrm{pH}$. Because $\mathrm{C}$. albicans can survive in a wide range of $\mathrm{pH}$ values, the $\mathrm{pH}$ may not be a critical factor in this situation. In addition, Calcium hydroxide solution may act as a source of free cationswhich have a critical role in morphogenesis and pathogenesis of C. albicans. [34] Furthermore, saturated Calcium hydroxide solutions are sensitive to inhibition, particularly by dentin, albumin, and hydroxyapatite. If the Calcium hydroxide solution does not have a backup reservoir of a paste, it may lose its high $\mathrm{pH}$ easily after interaction with organic and inorganic substances and may become ineffective. Ferguson et al. investigated antifungal effect of different irrigants and medications and concluded that the paste form of Calcium hydroxide was very effective in killing C. albicans although aqueous Calcium hydroxide had no antifungal activity [35]. Therefore, they stated that Calcium hydroxide must be in direct contact with microorganisms to show its potent an- 
timicrobial properties. In addition to different forms of Calcium hydroxide preparation, the microbiologic methods were also different in other studies.Ercan et al. used direct contact test and observed that C. albicans was more resistant than E. faecalis to Calcium hydroxide. Moreover, Gomes et al. investigated antimicrobial activity of Calcium hydroxide pastes by 2 methods: agar diffusion and direct contact tests.[36] They found that Calcium hydroxide pastes showed antimicrobial action only by direct contact test; they did not produce any inhibitory zone against any of the tested microorganisms. However, both studies used brain heart infusion broth or agar for growing C. albicans. Brain heart infusion is not a specific medium for fungi and may affect growth conditions of C. albicans [36, 37]. These discrepancies regarding antimicrobial effects of disinfectants may also be related to the strain type of $\mathrm{C}$. albicans used in different studies. Yeast cells have a high capacity of phenotypic switching and may rapidly gain resistance to antimicrobial agents [36-38].

\section{Conclusion}

Under the limits of the study, the above obtained results state that Saline was promoting the antibiotic effect whereas local anaesthesia and MTA were inhibiting the antibiotic activity of calcium hydroxide. On the basis of the results and of the experimental conditions used in the present study, antimicrobial activity of Calcium hydroxide against different microorganisms may change with the type of the vehicle. Additive antibacterial and antifungal action can be achieved by combining Calcium hydroxide with saline or distilled water. However, in vitro results should be carefully analysed before their adaptation to clinical use.

\section{References}

[1]. Nair PN, Sjögren U, Krey G, Kahnberg KE, Sundqvist G. Intraradicular bacteria and fungi in root-filled, asymptomatic human teeth with therapyresistant periapical lesions: a long-term light and electron microscopic follow-up study. J Endod. 1990 Dec;16(12):580-8.Pubmed PMID: 2094761.

[2]. Evans M, Davies JK, Sundqvist G, Figdor D. Mechanisms involved in the resistance of Enterococcus faecalis to calcium hydroxide. Int. Endod. J. 2002 Mar;35(3):221-8.

[3]. Kayaoglu G, Erten H, Bodrumlu E, Ørstavik D. The resistance of collagenassociated, planktonic cells of Enterococcus faecalis to calcium hydroxide. J Endod. 2009 Jan;35(1):46-9.Pubmed PMID: 19084123

[4]. Van Der Waal SV, De Soet JJ, Wesselink PR, Crielaard W. Calcium hydroxide treatment does not alter the susceptibility of Enterococcus faecalis biofilms to sodium hypochlorite. Eur. Endod. J. 2017;2(1):1.

[5]. Pavaskar R, Chalakkal P, Krishnan R, Sirikonda S, Vasepalli M, Venkataramana P. Study comparing the effectiveness of chlorhexidine, calcium hydroxide and linezolid based medicaments against enterococcus faecalis. J Clin Diagn Res. 2014 Mar;8(3):240-2.Pubmed PMID: 24783147.

[6]. Kovvuru SK, Hegde V, Manjunatha BS, Nagamahita V, Patil D. Evaluation of different $\mathrm{pH}$ levels of calcium hydroxide on Enterococcus faecalis: an in vitro study. Microbiol. Res. 2012 Jul;3(2):22.

[7]. Aakriti DB, Sharma P, Bhatt VD, Bhasin P, Arora E, Singh S, et al. Antimicrobial Potential of Calcium Hydroxide Chlorhexidine, Octenidol, Endoseptone and Combination of Calcium Hydroxide and Chlorhexidine against Enterococcus faecalis as Intracanal Medicament. J Pure Appl Microbiol. 2019;13(3):1725-35.

[8]. Żuk-Grajewska E, Saunders WP, Chadwick RG. Fracture resistance of human roots filled with mineral trioxide aggregate mixed with phosphate-buffered saline, with and without calcium hydroxide pre-medication. Int Endod J. 2021 Mar;54(3):439-453.Pubmed PMID: 33025614.

[9]. Tuna EB, Dinçol ME, Gençay K, Aktören O. Fracture resistance of immature teeth filled with BioAggregate, mineral trioxide aggregate and calcium hydroxide. Dent Traumatol. 2011 Jun;27(3):174-8.

[10]. Siqueira JF Jr, Lopes HP. Mechanisms of antimicrobial activity of calcium hydroxide: a critical review. Int Endod J. 1999 Sep;32(5):361-9.Pubmed PMID: 10551109
[11]. Piazza B. Evaluation of the antimicrobial activity, quality of removal and influence on the bond strength of calcium hydroxide pastes associated with different substances (Doctoral dissertation, Universidade de São Paulo).

[12]. Prathita T, Djauharie NK, Meidyawati R. Antimicrobial activity of mineral trioxide aggregate and calcium hydroxide sealer on enterococcus faecalis strain ATCC29212. Int. J. Appl. Pharm. 2019 Apr 5:123-5.

[13]. Barkhordar RA, Kempler D. Antimicrobial activity of calcium hydroxide liners onStreptococcus sanguis andS. mutans. J. Prosthet. Dent. 1989 Mar 1;61(3):314-7

[14]. Behnen MJ, West LA, Liewehr FR, Buxton TB, McPherson III JC. Antimicrobial activity of several calcium hydroxide preparations in root canal dentin. J. Endod. 2001 Dec 1;27(12):765-7.

[15]. Hemalatha R, Dhanraj S. Disinfection of Dental Impression- A Current Overview. Cuddalore. 2016 Jul;8(7):661-4.

[16]. Ramya G, Pandurangan K, Ganapathy D. Correlation between anterior crowding and bruxism-related parafunctional habits. Drug Invent. Today. 2019 Oct 15;12(10).

[17]. Anjum AS, Ganapathy D, Kumar K. Knowledge of the awareness of dentists on the management of burn injuries on the face. Drug Invent. Today. 2019 Sep $1 ; 11(9)$.

[18]. Inchara R, Ganapathy D, Kumar PK. Preference of antibiotics in pediatric dentistry. Drug Invent Today. 2019 Jun 15;11:1495-8.

[19]. Philip JM, Ganapathy DM, Ariga P. Comparative evaluation of tensile bond strength of a polyvinyl acetate-based resilient liner following various denture base surface pre-treatment methods and immersion in artificial salivary medium: An in vitro study. Contemp Clin Dent. 2012 Jul;3(3):298-301. Pubmed PMID: 23293485.

[20]. Gupta A, Dhanraj M, Sivagami G. Implant surface modification: review of literature. Internet J Dent Sci. 2009;7(1):10.

[21]. Indhulekha V, Ganapathy D, Jain AR. Knowledge and awareness on biomedical waste management among students of four dental colleges in Chennai, India. Drug Invent Today. 2018 Dec 1;10(12):32-41.

[22]. Mohamed Usman JA, Ayappan A, Ganapathy D, Nasir NN. Oromaxillary prosthetic rehabilitation of a maxillectomy patient using a magnet retained two-piece hollow bulb definitive obturator; a clinical report. Case Rep Dent. 2013;2013:190180.Pubmed PMID: 23533823.

[23]. Ganapathy DM, Joseph S, Ariga P, Selvaraj A. Evaluation of the influence of blood glucose level on oral candidal colonization in complete denture wearers with Type-II Diabetes Mellitus: An in vivo Study. Dent Res J (Isfahan). 2013 Jan;10(1):87-92.Pubmed PMID: 23878569.

[24]. Menon A, Ganapathy DM, Mallikarjuna AV. Factors that influence the colour stability of composite resins. Drug Invent Today. 2019 Mar 1;11(3).

[25]. Camargo CH, Bernardineli N, Valera MC, de Carvalho CA, de Oliveira $\mathrm{LD}$, Menezes MM, et al. Vehicle influence on calcium hydroxide pastes diffusion in human and bovine teeth. Dent Traumatol. 2006 Dec;22(6):302-6. Pubmed PMID: 17073921.

[26]. Soares JA, Leonardo MR, da Silva LA, Tanomaru Filho M, Ito IY. Elimination of intracanal infection in dogs' teeth with induced periapical lesions after rotary instrumentation: influence of different calcium hydroxide pastes. J Appl Oral Sci. 2006 Jun;14(3):172-7.Pubmed PMID: 19089068.

[27]. Velázquez S, Monzó JM, Borrachero MV, Payá J. Assessment of the Pozzolanic Activity of a Spent Catalyst by Conductivity Measurement of Aqueous Suspensions with Calcium Hydroxide. Materials (Basel). 2014 Mar 28;7(4):2561-2576.Pubmed PMID: 28788583.

[28]. Weiger R, Rosendahl R, Löst C. Influence of calcium hydroxide intracanal dressings on the prognosis of teeth with endodontically induced periapical lesions. Int Endod J. 2000 May;33(3):219-26.Pubmed PMID: 11307438.

[29]. Liang Y. Mechanical and fracture properties of calcium silicate hydrate and calcium hydroxide composite from reactive molecular dynamics simulations. Chem. Phys. Lett. 2020 Dec 16;761:138117.

[30]. Bilgi PS, Shah NC, Mehta J. Comparative evaluation of mixture of calcium hydroxide and chlorhexidine, with triple antibiotic paste and combination of calcium hydroxide, chlorhexidine, and lycopene on incidence of interappointment flare-up: an in vivo study. Int J Clin Dent Res. 2017;1(1):10-4.

[31]. Gomes BP, Souza SF, Ferraz CC, Teixeira FB, Zaia AA, Valdrighi L, et al. Effectiveness of $2 \%$ chlorhexidine gel and calcium hydroxide against Enterococcus faecalis in bovine root dentine in vitro. Int Endod J. 2003 Apr;36(4):267-75.Pubmed PMID: 12702121.

[32]. Delgado RJ, Gasparoto TH, Sipert CR, Pinheiro CR, de Moraes IG, Garcia RB, et al. Antimicrobial activity of calcium hydroxide and chlorhexidine on intratubular Candida albicans. Int J Oral Sci. 2013 Mar;5(1):32-6.Pubmed PMID: 23538639

[33]. Stavileci M, Hoxha V, Bajrami D, Dragidella A. Analysis of the effects of calcium hydroxide, chlorhexidine and mineral trioxide aggregate on the viability of Candida albicans. Dentistry. 2013;3(3).

[34]. Lačević A, Vranić E, Zulić I. Clinical application of calcium hydroxide in dental pathology and endodontics. Bosn J Basic Med Sci. 2003 Nov 


\section{0;3(4):26-9.}

[35]. Mohammadi Z, Dummer PM. Properties and applications of calcium hydroxide in endodontics and dental traumatology. Int Endod J. 2011 Aug;44(8):697-730.Pubmed PMID: 21535021.

[36]. Tronstad L, Andreasen JO, Hasselgren G, Kristerson L, Riis I. pH changes in dental tissues after root canal filling with calcium hydroxide. J. Endod. 1981 Jan 1;7(1):17-21.
[37]. Cunha LFM, Ehlers IFR, Brunini SHS. Comparison of changes in the $\mathrm{pH}$ of calcium hydroxide pastes associated with different vehicles. Dent. Press Endod. 2013;3: 32-5.

[38]. Engar RC. More on Calcium Hydroxide in Endodontics . J. Am. Dent. Assoc.. 2020;151:554. Available from: http://dx.doi.org/10.1016/j. adaj.2020.06.007 